\title{
Furor y valor: traslaciones épicas desde Lucano hasta Anchieta y Ercilla
}

\author{
"Furor" and "Valor": Epic Translations \\ from Lucan to Anchieta and Ercilla
}

Jobst WeLGe

Romanische Literaturwissenschaft und Kulturstudien Institut für Romanistik

Universität Leipzig

Beethovenstr. 15. Leipzig, 04107. Alemania

welge@zedat.fu-berlin.de

Orcid ID 0000-0002-4271-4269

Resumen: Este artículo se basa en la comparación entre una de las primeras epopeyas coloniales, De Gestis Mendi de Saa (una obra neo-latina escrita por el padre jesuita brasileño José de Anchieta) y la más conocida epopeya sobre el Chile colonial, La Araucana de Ercilla. El ensayo sigue el estudio seminal de David Quint sobre el género épico clásico y de la temprana modernidad y muestra cómo los dos textos sobre conflictos militares en América Latina se relacionen con las convenciones genéricas de los modelos clásicos, especialmente La Eneida de Virgilio y La Farsalia de Lucano. De modo diferente, las dos epopeyas combinan la retórica imperialista de Virgilio con el discurso más crítico de Lucano, lo cual introduce una cierta empatía hacia el enemigo. En especial se señala que los pueblos indígenas de Brasil y Chile se representan a través de un imaginario tanto de barbarie como de nobleza. De esta manera, los textos crean modos diferentes de adaptación genérica y de ambivalencia ideológica.

Palabras clave: Epopeya. Anchieta. Ercilla. Representación de los pueblos indígenas. Imperialismo.
RECIBIDO: 19 DE FEBRERO DE 2018 ACEPTADO: 6 DE JUNIO DE 2018
Abstract: The following essay is based on a comparative discussion of one of the first colonial epics, De Gestis Mendi de Sa (a Neo-Latin work written by the Brazilian Jesuit José de Anchieta) with the much more well-known epic about early colonial Chile, La Aracaucana, by Ercilla. Following the seminal work on classical/early modern epic by David Quint, the essay outlines how the two epics about military conflicts in Latin America are related to the generic conventions of the classical paradigms, notably Vergil's Aeneid and Lucan's Pharsalia. To varying degrees, both epics blend the imperial rhetoric of Virgil with the more critical language of Lucan that allows for a certain amount of sympathy with the side of the enemy. Specifically, I argue that the indigenous populations of Brazil and Chile are poetically represented with categories of both savagery and nobility -thus achieving different varieties of generic adaptation and of ideological ambivalence.

Keywords: Epic. Anchieta. Ercilla. Representation of Indigenous People. Imperialism. 
L

as convenciones épicas, con sus encuentros de culturas diversas, de confrontación militar, sus relatos de autoridad y poder, de fundación de naciones e imperios, existen, per definitionem, en una red de textos y discursos relacionados a través de complejos planos de mimesis, imitación y rivalidad. Si esto ya implica una relación dinámica entre las culturas de la Antigüedad y del Renacimiento europeo, nos encontramos con otra categoría más en el juego textual cuando se trata de una obra escrita o situada en el Nuevo Mundo, que a veces ha sido percibido como, justamente, una nueva Antigüedad. ¿De qué se trata, entonces, cuando ciertas imágenes y convenciones épicas viajan desde el Mundo Antiguo a la Temprana Modernidad, y desde Europa hasta el Nuevo Mundo? Cabe recordar que, tradicionalmente, la forma épica se concentra en el reino del pasado y en los valores de una comunidad, según la conocida fórmula de Mikhail Bakhtin: "The world of the epic is the national heroic past: it is a world of «beginnings» and «peak times» in the national history, a world of fathers and of founders of families, of «firsts» and «bests»" (Bakhtin 13). ${ }^{1}$ En contraste con este modelo, los casos de las epopeyas renacentistas de las naciones imperialistas, como, por ejemplo, Os Lusíadas (1572) de Camões, nos enfrentan al problema de cómo la forma épica tiene que adaptarse a las exigencias y los topoi de la forma clásica (en especial, la profecía), en un contexto "histórico" de la (casi) contemporaneidad (Nicolopulos). Como veremos, tanto Anchieta como Ercilla ponen en escena las posibles contradicciones entre forma heredada y tema presente.

Podríamos distinguir, tal vez, entre varios efectos de traslaciones épicas en ese nuevo contexto: el cambio de procedimientos semánticos que ya no funcionan en el modo tradicional; la afirmación o la ambivalencia ideológica en relaciones de colonización y de imperialismo; y la función de una valorización o de ennoblecimiento de culturas no europeas -y esto, paradójicamente, a través del uso de una forma literaria europea-. Estas diversas tendencias han sido exploradas en estudios literarios recientes. Por ejemplo, Barbara Fuchs, en su libro Mimesis and Empire, escribe lo siguiente:

The mimetic conventions of epic do not travel well to the New World.

There the competing discourse of ethnography and the pressures of con-

1. Ver también Conte 1986, 142-43: "The epic code is the medium through which society takes possesion of its own past and gives that past the matrix of a model. Thus the epic code is the preliminary level of that elaboration whose purpose is the literary organization, in narrative form, of collective cultural values". 
temporary empire-building undermine literary verities with first-hand knowledge of different peoples and their different motivations. (48)

David Quint, por su lado, en su libro fundamental Epic and Empire, ha demostrado que existe una rivalidad (además de una combinación) entre los códigos de la épica de los vencedores y la de los vencidos. Los modelos paradigmáticos son, de un lado, el imaginario imperial en la Eneida de Virgilio y el imaginario republicano en la Farsalia de Lucano. Finalmente, David E. Lupher, en su libro Romans in a New World, ha estudiado, desde una perspectiva genérica más amplia, los varios efectos de la asociación imagística de los pueblos indígenas con el mundo histórico de los antiguos romanos, afirmando de esta manera el orgullo del pueblo colonizador.

En las páginas siguientes me voy a basar en estas tres aproximaciones recientes a la cuestión de la épica en el Nuevo Mundo. Más específicamente, quisiera comparar dos textos muy diversos entre sí, y que nunca, que yo sepa, han sido enfrentados. Esta comparación parte de una observación aparentemente muy sencilla, a saber, la circunstancia de que son dos obras épicas que combinan (en el sentido de David Quint) la influencia de Virgilio (Eneida) y la de Lucano (Farsalia). Me gustaría demostrar que el recuerdo de Lucano y de su poema de orientación republicana es responsable de una cierta ambivalencia acerca de la representación de la confrontación entre colonizadores y mundo indígena, y que esa ambivalencia, a través de elementos semánticos que designan crueldad y furor, puede manifestarse en modos diversos. A pesar de la utilidad de la confrontación formal-ideológica propuesta por Quint (épica de los vencedores $v$ s. épica de los vencidos), es importante constatar que dentro la misma Eneida ya se pueden identificar elementos que muestran una cierta ambivalencia de la ideología imperial, de resistencia al modelo homérico de conclusión y cumplimiento. Precisamente estas resistencias a la estructura supuestamente teleológica de la Eneida se repiten en muchos ejemplos de la épica post-virgiliana (Kennedy 151).

Lucano (39-65 d.C.) vivió obsesionado con el fin de la República romana y murió al ser descubierto como conspirador contra el emperador Nerón. $\mathrm{Al}$ contrario de la tradición precedente, fue la Farsalia (o Bellum Civile) la primera épica basada en eventos históricos recientes. La Farsalia (cuyo nombre designa la batalla decisiva de la segunda guerra civil entre César y Pompeyo Magno en 48 a.C.) es un poderoso sermón político a favor de una causa derrotada: el lado republicano abandonado por los dioses, pero mantenido por el espíritu estoico de Catón. Es casi proverbial una frase del primero libro de 
la Farsalia: "Victrix causa deis placuit, sed victa Catoni" (Lucano 1988 I, 128) [La causa vencedora plugo a los dioses, pero la vencida, a Catón] (Lucano 1984, 37). Mi segundo ejemplo de un poema épico escrito bajo la influencia de Lucano es el texto más paradigmático, complejo y conocido dentro de este contexto, a saber, La Araucana de Alonso de Ercilla y Zúñiga (1533-1594). Mi primer ejemplo, en cambio, es un texto mucho menos conocido, pero significativo en la medida en que precede por unos pocos años la publicación de la primera parte de La Araucana; una obra que es, de hecho, la primera epopeya escrita en el Nuevo Mundo, en Brasil: De Gestis Mendi de Saa ("Las Hazañas de Mem de Sá”), del padre jesuita José de Anchieta (1534-1597). Aunque se trata de una obra neolatina de poca influencia en su época, vamos a ver que participa a su manera en el discurso colonial contemporáneo. La comparación de estas dos epopeyas renacentistas intenta resaltar cómo la memoria literaria (sobre todo de Lucano) refuerza la ambivalencia ideológica de un género altamente político. En mi lectura (necesariamente muy parcial) de los dos poemas me voy a concentrar especialmente en los momentos que describen aspectos semánticos o negativos (ferocidad, furor) o positivos (valor) que a veces sugieren una similitud entre los partidos opuestos.

\section{ANCHIETA: DE GESTIS MENDI DE SAA}

José de Anchieta (1534-1597) fue un misionero jesuita (miembro de la Compañía desde 1551) y un humanista de extraordinarios conocimientos lingüísticos. Su obra literaria se compone de diversos géneros (prosa, poesía, autos, sermones) y varios idiomas: castellano, portugués e incluso la lengua general tupí-guaraní, además del latín. Por ejemplo, fue el autor de la primera gramática de la lengua tupí. Su público lo formaban, por un lado, los indios brasileños (por su producción dramática) y, por otro, los colonizadores portugueses que leían sus obras (Metcalf 98-99). De Gestis Mendi de Saa ha sido considerada la primera epopeya de las Américas (1563), cuyo tema son "los descubrimientos de nuevas tierras y la evangelización de sus gentes", a saber, aquellos acontecimientos históricos que consolidaron definitivamente la colonización portuguesa en Brasil (González Luis 720). Además, la obra es el primer poema brasileño publicado (Coimbra 1563), si se considera que no existían prensas de imprenta en Brasil antes de la Independencia. Con todo, un facsímil de la editio princeps se publicó en Brasil solo en 1997, circunstancia que explica su influencia limitada en su época. ${ }^{2}$ Anchieta, nacido español en Tenerife (1534), 
pasó cinco años en Portugal, donde estudió en el Colégio Real das Artes, antes de viajar a Brasil. Allí pasó el resto de su vida y se lo conoce como una figura central de la historia cultural del país, en especial del sincretismo cultural tan distintivo de la cultura brasileña (Pereira 9-10).

De Gestis Mendi de Saa, escrita entre 1560 y 1562, parte del contexto histórico de la colonización portuguesa de Brasil y se concentra en las campañas militares contra los pueblos indígenas y el proyecto ideológico de su evangelización. Además, cuenta las iniciativas de asentamiento de los franceses -con su jefe Durand de Villegaignon- en la colonia y la posterior intervención del tercer gobernador, Mem de Sá, para desalojarlos (fue gobernador desde 1558 hasta 1572). Los franceses se habían establecido en la isla de Serigipe desde 1555, dentro de la bahía de Guanabara, cerca de Río de Janeiro, una colonia llamada France Antarctique (Anchieta 722). La disputa por la hegemonía del territorio se complicó con el papel de las tribus indígenas, que se aliaron con los dos poderes, a fin de fortalecer sus propias guerras internas (Lestringant).

Concebido como un poema cristiano, la obra de Anchieta describe una guerra "santa" en dos fronteras: es decir, contra el poder rival de los franceses "heréticos", y contra el salvajismo de los indios paganos. Como epopeya renacentista vinculada a la historia reciente, la intención del poema es celebrar eventos sucedidos desde 1557, cuando Mem de Sá llega a Brasil, hasta 1560, año de la victoria portuguesa.

Nos interesa aquí la cuestión de cómo las tribus indígenas están representadas, y, especialmente cómo la forma épica presenta a la vez la agresión colonial y la empatía evangelizadora. Primero, constatamos que el poema celebra al gobernador al servicio de la corona portuguesa, Mem de Sá, todavía vivo en el momento del elogio, como el instrumento divino y como héroe/soldado cristiano que ha sometido a sus rivales franceses y a los indios resistentes. Así, se celebra al gobernador en la panegírica Epistola Nuncupatoria a él dirigida, la cual abre el poema, como "rector magnus; pius Mendus; fortis rector; magnus praetor; pius praetor" ["grande soberano; pío Mendo; fuerte líder; grande jefe; pío jefe”] (Anchieta 723). ${ }^{3}$ En otras palabras, a través de su insistente cualificación como "pius", Mem de Sá ocupa la función del héroe

2. En los siglos siguientes, la historia literaria brasileña conocerá algunas épicas en lengua vernácula, como, por ejemplo, O Uraguai, de José Basílio da Gama (1769).

3. La traducción (aproximada) del poema de Anchieta es mía. 
épico en la tradición de Eneas, a la vez que cumple su papel de héroe cristiano. De hecho, el poema se esfuerza en conciliar las hazañas militares con el programa de una retórica cristiana.

El primer libro describe la condición de barbarie de los indios antes de la llegada de los portugueses y de su benigno gobernador. Aquí se celebran especialmente las hazañas del hijo del gobernador, Fernão de Sá, el cual obtuvo diversas victorias militares contra los indios antes de morir en plena batalla. El segundo libro hace hincapié en el sometimiento del jefe indio $\mathrm{Cu}-$ rurrupeba, cuyo nombre, nos explica el narrador, puede ser traducido como "bufo planos", es decir, un sapo, un animal asociado con las fuerzas del mal y de la concupiscencia. Además, esta parte celebra la praxis misionera por la cual la existencia nómada de los indios (asimilados a "leones vagabundos") se domestica a través de los llamados "aldeamentos" (Anchieta 1030). El tercer libro es el más extenso y cuenta, tras otra batalla contra los revoltosos indios, mediante una digresión retrospectiva, la muerte del primer obispo de Brasil, Fernandes Sardinha. Este, tras sobrevivir a un naufragio, llega a la orilla del mar, donde es asesinado y devorado por los caníbales caetés. Dicho sea de paso, este famoso episodio inspira la irreverente datación del Manifesto Antropófago (1928) del modernista brasileño Oswald de Andrade: "Ano 374 da Degluitação do bispo Sardinha" (Andrade 52). Después de la batalla contra los indios, Mem de Sá recibe órdenes de atacar a los franceses, aliados de la tribu de los Tamoios. La narración de esta batalla ocupa el cuarto libro, el cual concluye con la destrucción del fortín francés de Coligny en la bahía de Guanabara.

El salvajismo de los indios se muestra, sobre todo, en la práctica del canibalismo. Se trata, de hecho, de un punto crucial, muy frecuente en la retórica misionera de los jesuitas. En el poema, la barbarie y especialmente el "furor" (esta última, como veremos más adelante, categoría eminentemente “épica”) de las tribus indígenas “indómitas” están representados con imágenes textuales o metáforas del reino animal, a saber: serpientes, tigres y leones, aunque los dos últimos no formaran parte de la fauna brasileña. Sin embargo, es interesante notar que la imagen del león sangriento se asocia no solo a los indios "salvajes", sino también al hijo del gobernador, Fernão de Sá:

[...] ceu frendentem cum turba leonem

Cingit, et infestat iaculis, ille improbus ira

Rugit atrox, et torva tuens, hunc impetit aut hunc

Impavidus laniatque artus ferus ore cruento; 
Illi instant, figuntque hastas per terga, per armos

Certati, donec confossus vulnere multo,

Occumbit, laeditque immani corpore terram. (Anchieta 635-41) ${ }^{4}$

Este imaginario del león salvaje y del "furor" de la guerra es ya conocido en la épica clásica, por ejemplo en la caracterización de Turno, el anti-Eneas, en el poema de Virgilio: "saevit amor ferri et scelerata insania belli" ["crece en él la sed de armas y el malvado frenesí de la guerra"] (VII, 461); ${ }^{5}$ o en la descripción de César en la Farsalia (Lucano 1988 xx). ${ }^{6}$

El hecho de que el padre Anchieta distribuya este imaginario metafórico del animal violento -o de una violencia animal- algo simétricamente entre los colonizadores portugueses y los indios caníbales ${ }^{7}$ es señal por lo menos de una cierta ambivalencia moral, la cual, sin embargo, no forma parte de la ideología explícita y "oficial” del poema. En esa línea de mi argumentación, sigo el reciente y rico artículo de Alessandro Moura, quien escribe: "the extreme brutality of Lucan's Civil War and Statius' Thebaid and their ambivalence in the treatment of epic virtus make them crucial models for exaggerating the savagery of the Indians whilst questioning the heroism of the Portuguese" (Moura 1). Al contrario del poema de Virgilio, cuya influencia se nota también en la épica de Anchieta, los otros dos poemas latinos, asociados con la llamada época de plata en la historia literaria romana, enfatizan especialmente la violencia destructiva de una guerra civil. Así, el motivo del "amor por la guerra", la perversión de la virtud militar por medio de la violencia autodestructiva, ya se encuentra en el comienzo de la Farsalia: "si tantus amor belli tibi, Roma nefandi" (I, 21) ["si tu amor de una guerra nefanda es tan grande, Roma”] (Lucano 1984, 37). Esta crítica de la guerra, en cierta medida presente incluso en Virgilio, adquiere una dimensión mucho mayor en Lucano y Estacio (Tebaida).

4. El subrayado es mío. [... como cazadores alrededor del león que tiembla; él hace estragos horriblemente y amenaza ferozmente con una mirada furiosa, impávidamente rasga con la boca ensangrentada los cuerpos que alcanza: ellos lo aprietan, le echan lanzas en las espaldas y en los hombros, hasta que todo perforado de heridas sucumbe].

5. Otra vez, la traducción es mía.

6. En la época del Renacimiento, cabe citar el ejemplo de Gargantua et Pantagruel de Rabelais, una epopeya paródica, en la cual (en la parte Gargantua) el tirano Picrochole lanza una guerra contra Grandgousier (padre de Gargantua) y es constantemente asociado con la marca negativa del furor ("fureur"), así aludiendo a la figura de César en la Farsalia (Rabelais XXV-XXVI, 138-47).

7. "Laniatu vivere tigris / Desinat; aut vitulos saevi lacerare leones, / Innocuasve lupi pecudes?" (Anchieta 961-63) [Pueden los tigres viver sin matar y los leones feroces dejar de abatir los terneros y los lobos perdonar el manso ganado?]. 
De hecho, la preocupación central de Lucano era justamente la representación del cuerpo dividido de la guerra civil romana (Quint 141). El poema de Lucano pone mucho énfasis en el poder de los animales carnívoros, como "el tigre feroz y león enojado" ("avidae tigres et nobilis ira leonum", VI, 438). También se centra en las mutilaciones corporales, como la violencia ejercitada por la hechicera Ericto sobre los cuerpos muertos de los soldados en el desierto de Tesalia (VI, 538-68); o la escena en la cual animales feroces devoran los cuerpos corruptos de los soldados (VII, 825: "Non solum Haemonii funesta ad pabula belli / Bistonii venere lupi tabemque cruentae / Caedis odorati Pholoen liquere leones") ["Al fúnebre festín de la guerra hemonia no acudieron solo los lobos bistanios, sino que, a olor de la podre de la sangrienta carnicería, dejaron el Foloe los leones" (Lucano 1984, 231)]. Así, Lucano explora las fronteras entre lo humano y lo animal. En el contexto de la guerra civil romana, Lucano también invoca varios episodios de violencia atroz, inclusive el espectro del canibalismo, cuando la cabeza sangrienta de Antonio es depositada sobre la "mesa festiva": "aut te, praesage malorum / Antoni, cuius laceris pendentia canis / ora ferens miles festae rorantia mensae / Inposuit" (II, 122-23) [“o para aludir a ti, Antonio, présago de nuestras desgracias, cuya cabeza, llevándola colgante de los ajados mechones blancos un soldado, la depositó, todavía chorreando sangre, en la mesa del festín" (Lucano 1984, 64).

"Tessalia infelix" (VII, 847; VI, 333) es el lugar del encuentro decisivo de los ejércitos de César y Pompeyo. En una escena famosa de necromancia la hechicera Ericto, consultada por Sexto Pompeyo, uno de los hijos de Pompeyo, está profetizando la tragedia que amenaza a Sexto, su familia y todo el sistema político de Roma. Para Lucano, las fuerzas negativas de la "ira” y del "furor" están personificados en el héroe oscuro César; es este último quien representa aquellas fuerzas oscuras irracionales que han sido vencidas en la Eneida de Virgilio (Conte 1992, 351). Estos son atributos típicos del tirano, presentes ya en la tragedia romana arcaica y reciclados en el teatro de Séneca. En esta tipología entran también la ferocidad y la crueldad, y en la Farsalia Lucano priva a Julio César de su atributo tradicional -la clemencia por los vencidos- y de esta manera lo separa de la virtud principal de Eneas (Conte 1992, 351).

Si Anchieta, entonces, ha heredado de Lucano el tema de la violencia animal y del furor indomable, al mismo tiempo tiene que distanciarse del pesimismo histórico del poeta latino (Rodríguez-Pantoja). Las imágenes más 
drásticas relacionadas con el mundo del infierno, Anchieta las reserva para las herejías del protestantismo, es decir, el calvinismo de los franceses:

Magna ibi librorum stabat congesta suppelex,

Qui fidei claudunt aliena atque impia scita:

Quae vel Martinus perversa mente Lutherus

Composui, docuitque suos servare nepotes;

Pontificem contra blasphemo plurima summum

Ore fremens contraque tuam, Christe optime, sponsam

Vel quae Ioannes impuro Brentius ore,

Martini proles, infami digno parente;

Vel vomuit petulans foetenti e corde Melanthon.

Hic quod (quam Stygia nuper ructavit ab unda

Tartarus, illuvie foedam, multisque tumentem

Belua multiplici serpens turpissima lapsu

Quae vomuit quondam colubrorum turba venenis),

Calvinus, spiris multoque volumine turrim

Complectens aderat, flammantis lumina torquens

Letiferoque vibrans linguam stridore bisulcam. (Anchieta 2882-2909) ${ }^{8}$

Es significativo que esta invectiva contra los franceses y su orientación confesional está marcada por una isotopía de lo infernal, además de una asociación con serpientes; en otras palabras, imágenes que claramente recuerdan La Farsalia, especialmente el libro VI. Las doctrinas de Melanchthon y de Lutero son simbólicamente asociadas con dragones infernales; de Calvino se dice por ejemplo que es una serpiente. Esa forma de "ira" herética, al contrario de la "ira" de César en la Farsalia, llega a ser pacificada por el poder de Cristo: "In cineres rapidis iam tecta superba redegit / Ignis et effrentes Dominus compescuit iras" (Anchieta 2940): ["Fue el señor quien domesticó esas iras sin fronteras, fue él quien extirpó su arrogancia”].

8. El subrayado es mío. [Allí se encontraba un mueble, lleno de libros, que encerraban doctrinas tachonadas de impiedades y errores. / Martín Lutero las compuso con mente perversa / y mandó a sus nietos seguirlas estrictamente. / Indignado, arrojó muchas blasfemias contra el papa, sumo pontífice, y contra la iglesia, esposa de Cristo. / Muchas otras vomitó de sus labios impuros / Johannes Brenz, raza de Lutero y digno de infamia paternal: / y el malhumorado Melanchthon de corazón maloliente. / Allí también estaba la bestia que los abismos del infierno recientemente eructaran de sus barros inmundos, / dragón hinchado de todo el veneno que el mundo preparó en sus monstruos. / Es Calvino, la serpiente de movimiento variado y horrendo, / que abraza con sus espirales la torre, vibra miradas de fuego / y agita la lengua tripartita con ruido de muerte. 
Si se ha considerado el poema de Ercilla como una epopeya cristiana (Lagos), esto vale aún mucho más para el caso de la de Anchieta, verdadera obra de la Contrarreforma. Esta transformación cristológica del género épico había sido realizada ya en la tardía Antigüedad y fue después retomada por el escritor italiano Jacopo Sannazaro (De partu Virginis 1526). A pesar de sus vacilaciones éticas, el poema de Anchieta se basa en el concepto de una psychomachia, es decir, un enfrentamiento simbólico-espiritual entre las fuerzas personificadas del Bien y del Mal, entre Mem de Sá y el diablo.? En esta perspectiva, el gobernador Mem de Sá es el héroe cristiano, el redentor e instrumento de Dios, que tiene que enfrentar dos enemigos a la vez: por un lado, los indios brasileños, bárbaros y antropófagos, por otro lado los colonizadores franceses de la llamada France Antarctique. En este bifrontismo se muestra la función doble de Mem de Sá como gobernador militar y representante de una política religiosa de evangelización por parte de los jesuitas. Estos dos enfrentamientos representan, digámoslo así, una "acción paralela", que se dirige contra los dos enemigos paganos o heréticos. De esta manera, el poema del padre jesuita hace parte de una constelación discursiva más amplia, que incluye, por ejemplo, escritores franceses como Montaigne y Jean de Léry, que en sus obras habían polemizado contra la violencia de las guerras religiosas en Francia, basándose en un paralelismo simbólico entre el debate sobre la presencia real de la eucaristía en el rito católico y el escándalo -o no- de la práctica de la antropofagia entre los indios del Brasil. ${ }^{10}$ De modo muy diferente funciona este paralelo en Anchieta: para el escritor católico, la praxis de la eucaristía aparece aquí como una sublimación positiva, redentora, de un rito originalmente bárbaro o la herejía protestante de no creer que el pan encierra el cuerpo de Cristo ("Nec credit panis claudi sub imagine Christum"; Anchieta 2915). Los indios no aparecen aquí en forma tan noble, a la manera de los antiguos romanos, como en Ercilla. Al contrario, son constantemente designados como "bárbaros" o animales feroces; pero a veces la descripción detallada de sus costumbres, de su medio ambiente y de la naturaleza tropical puede verse como el núcleo del nativismo de la futura literatura brasileña (Frohwein de Salles Moniz

9. Sobre la simbología satánica en la épica colonial, ver Cañizares-Esguerra 25-82; sobre Anchieta, Cañizares-Esguerra 40.

10. Ver la discusión del poema en el contexto de los debates sobre la eucaristía por Briesemeister. Para las implicaciones martirológicas en el cruce de canibalismo y catolicismo, ver Mahlke 56-64. 
193-94). Concretamente, esto implica que, cuando el poeta describe cómo los indios se preparan para una batalla (la batalla de Cricaré), los describe primeramente como "feroces" ("acrior"), de "manos bárbaras" ("barbara [...] dextra"), y de "hábitos crueles" ("gestatque feros crudelis usus"; Anchieta 318-40), para después expresar una imagen bastante positiva y casi estetizante de sus trajes y de sus ornamentos ("Ornarunt alis auium capita ardua multi, / Plurima pendentes pexo redimicula crine") ["Muchos ornaban las cabezas con plumas de pájaros, colgando varios cordones en los pelos peinados"]. Sin embargo, a pesar de esa apreciación del ornatus, el juicio de este fragmento en su conjunto consolida la perspectiva negativa y alarmada ante la otredad supuestamente incivilizada: "Atque alios aliosque habitus per nuda dedere / Membri feri, horribiles uisu, uultuque minaces" (Anchieta 339-40) ["Y los salvajes amenazadores presentaban muchos trajes, aterradores para ver, los miembros desnudos y la cara"].

En Anchieta, la representación de los enemigos indios constantemente confunde la crítica del furor militar con la práctica del canibalismo: "furit imis ira medullis / Et belli vesanus amor carnisque cupido / Humanae" (Anchieta 213-15) ["Ira en sus corazones, amor maníaco de la guerra y el deseo por la carne humana”]. A despecho de la clausura ideológica y del tono oficialmente triunfante del poema, la línea final de la obra invoca la antropofagia brasileña como un problema abierto y todavía no resuelto: "Natio, quae humana pascit fera viscera carne" (Anchieta 3051) ["una nación cuyas vísceras se nutren de carne humana"]. La palabra "viscera" recuerda de hecho los versos del comienzo de la Farsalia: "canimus [...] populumque potentem / In sua victrici conversum viscera dextra" (I, 2-3): "Cantamos [...] un pueblo poderoso [...] que se revolvió contra sus propias entrañas" (Lucano 1984,72$)$.

A fin de cuentas, se puede decir que Anchieta estaba vacilando entre una política de esclavización o exterminio y los varios recursos para "civilizar" a los brasileños (Moura 8). Probablemente, y a través de las alusiones literarias mencionadas, Anchieta insinuó también una forma de canibalismo escondido por parte de los colonizadores (Moura 9). Así, contra el discurso oficial del poema, emerge (en cierta medida) una similitud inquietante entre los campos opuestos, que enfatiza la tendencia a la autodestrucción y la violencia "indómita" en el mismo campo de los portugueses. Esas ambivalencias y la ubicuidad del diablo en la épica se transfiguran a través de las manifestaciones del providencialismo cristiano (Cañizares-Esguerra 40). 


\section{ERCILLA: LA ARAUCANA}

La Araucana apareció después del retorno a España de su autor, en intervalos de una década: 1569,1578 y 1589. Ercilla había llegado a Chile en 1557 al servicio de Felipe II y había servido dos años en las guerras contra los rebeldes araucanos, después de que los indios hubieran matado al gobernador, Pedro de Valdivia. Así pues, quisiera brevemente recordar algunos elementos de la celebrada ambivalencia que caracteriza a La Araucana. Los araucanos de Chile son también representados como seres feroces y bárbaros. Sin embargo, al contrario del poema de Anchieta, aquí se representan bastante estilizados, como si fueran venerables héroes homéricos o miembros de una vieja clase aristocrática (Quint 174). Al contrario de los indios de Anchieta, los araucanos ya se habían convertido al cristianismo, y por eso el narrador de La Araucana hace hincapié en la rebelión indígena contra esa primera conversión (anterior a la llegada de Ercilla), considerada como quebramiento de una fe jurada: "pero que si quisiesen convertirse / a la cristiana ley que antes tenían, / y a la fe quebrantada reducirse / que al grande Carlos Quinto dado habían” (Ercilla XVI.30).

El jefe indio Caupolicán, responsable de los sucesos militares en la primera parte del poema, es representado como una figura altamente dignificada y noble; su muerte violenta, que concluye el descuartizamiento, pinta el colonialismo español con una connotación negativa sumamente crítica. El poema épico de Ercilla justifica el expansionismo español, pero genera también empatía por el campo opuesto, en parte porque la representación del "otro" se parece extrañamente a la auto-representación del poder imperial. ${ }^{11}$ Esta ambivalencia potencialmente perturbadora ya fue notada por el mismo Ercilla en su prefacio en prosa al poema: "[...] que me muestro algo inclinado a la parte de los araucanos, tratando sus cosas y valentias más estendidamente de lo que para bárbaros se requiere" (Ercilla 69). De hecho, las primeras dos estrofas ya presentan la postura de ambivalencia que se mantiene en todo el poema. Por un lado, el poeta exalta (revistando los famosos incipit de Virgilio y Ariosto) "el valor, los hechos, las proezas / de aquellos españoles esforzados” (Ercilla I.1); por otro lado, los araucanos son designados como "harto notables / de gente

11. Martínez 133: "The Chilean Indians resemble not only the Roman imperial armies but also the Numantines, the ancient Spaniards -in Golden Age antiquarian discourse- who heroically resisted the Roman empire". 
que a ningún rey obedecen" (Ercilla I.2). Como ya varios críticos han observado, existe en el poema cierta correspondencia entre la circunstancia de que el escritor era, en parte, testimonio ocular de los eventos recientes y una poética de la interrupción y fragmentación, la cual retoma unas técnicas narrativas de suspensión, usadas por Ariosto en su Orlando Furioso (1532). ${ }^{12}$ De hecho, Ercilla invoca la autoridad de lo inmediato y auténtico; por eso, insiste en su estatuto de "un buen testigo" (Ercilla I.5), que ha escrito en apariencia muchos versos directamente en los intersticios de las batallas a las cuales ha asistido: "porque fuese más cierto y verdadero, se hizo en la misma guerra y en los mismos pasos y sitios, escribiendo muchas veces en cuero por falto de papel, $y$ en pedazos de cartas, algunos tan pequeños que apenas cabían seis versos, que no me costó después poco trabajo juntarlos" (Ercilla 69).

Sin embargo, el poema contiene también una escena típica de profecía -según las convenciones épicas- que obviamente trasciende la observación directa del testigo y sirve para una visión más amplia del desarrollo de la historia imperial. Esta escena recuerda a través de muchos detalles a la de la hechicera Ericto en el libro vI de la Farsalia, a saber, la escena espectacular de necromancia (nekyomanteia) con un soldado muerto mágicamente resucitado. Se trata de un pendant de la catábasis de Eneas, escena que sucede también en el libro VI de la Eneida, a mitad del poema. Es probable que Lucano quisiera extender su poema, de modo paralelo al de Virgilio, hasta un total de doce libros (Conte 1992, 350). En La Araucana, la invocación por parte de Fitón de las Furias del infierno es, posiblemente, una alusión intertextual a la figura de Ericto en la Farsalia (vI, 655-56), ya que se la compara con una Furia infernal:

¡Y vos, Furias, que así con crueldades

atormentáis las ánimas dañadas, que aún temen ver las ínferas deidades vuestras frentes de víboras crinadas; y vosotras, gorgóneas potestades por mis fuertes palabras apremiadas, haced que claramente aquí se vea, aunque futura, esta naval pelea! (Ercilla XXIII.90)

12. Observa Fuchs 38: "The fragmented shape of the text corresponds to fractures in its imperial ideology". 
Sin embargo, esta visión del poderoso Fitón en su caverna se asocia a la figura de Merlín en el Orlando Furioso de Ariosto (xxxIII, donde su capacidad profética está asociada con el arte), además de otras escenas de profecía en Virgilio y Lucano. Por lo tanto, por esas asociaciones intertextuales y metapoéticas, el mago puede verse como un doble del mismo poeta. Por otro lado, este pasaje contrasta con una escena anterior, en el primer libro de la Araucana, que, en modo casi etnográfico, describe la práctica de la magia entre los araucanos:

Usan el falso oficio de hechiceros, ciencia a que naturalmente se inclinan, en señales mirando y en agüeros por las cuales sus cosas determinan; veneran a los necios agoreros que los casos futuros adivinan: el agüero acrecienta su osadía y les infunde miedo y cobardía. [...] Estos son los que ponen en errores al liviano común con su elocuencia, teniendo por tan cierta su locura, como nos la Evangélica Escritura. (Ercilla I.42-43)

La superposición textual de las dos escenas de profecía relaciona la práctica "loca" de los araucanos con su modelo épico, que en Lucano había llegado a ser una versión pervertida y negativa del topos teleológico de la épica clásica. Sin embargo, esta dudosa autoridad del hechicero araucano constituye al mismo tiempo un contraste y un paralelo con la autoridad del poeta, invocada y repetida programáticamente: "No es poético adorno fabuloso / mas cierta historia y verdadero cuento, / ora fuese algún caso prodigioso / o extraño agüero y triste anunciamento" (Ercilla XVI.23).

La representación, aparentemente sincera por parte de Ercilla, de la bravura militar de los araucanos aparece, especialmente en la segunda parte del poema, como una forma de patriotismo suicida. Es significativo, pues, que el canto se abra justamente con una invocación de la patria que sirve para universalizar los actos y sentimientos de los araucanos (Ercilla XXIX.1). El último canto de la segunda parte (XXIX), que habla de la autoinmolación de los indios desperados, comienza con una invocación retórica de figuras clásicas del suicido patriótico, entre otros el de Catón de Utica: 
Buen testimonio desto nos han sido

las hazañas de antiguos señaladas,

que por la cara patria han convertido

en sus mismas entrañas las espadas,

y su gloriosa fama han estendido

las plumas de escritores celebradas. (Ercilla XXIX.2)

Esta alusión al suicidio de Catón -quien tomó el partido de Pompeyo contra César- como culminación de una serie de suicidios patrióticos romanos es un buen ejemplo de cómo la referencia a una ejemplaridad romana puede asumir la perspectiva de los vencidos (en el sentido de Quint), y, por eso, el modelo literario de Lucano (Lupher 304). ${ }^{13}$ No cabe duda de que esta invocación del militarismo estoico y de la inmovilidad frente a la muerte está también bajo la influencia del estoicismo y de Séneca. En todo caso, la caracterización de los combatientes araucanos establece una oscilación semántica entre furor y valor, como en el duelo extendido entre Tucapel y Rengo:

Redoblan los segundos de manera

que aunque fueron pesados los primeros,

si tal reparo y prevención no hubiera,

no llegara el combate a los terceros.

¡Quién por estilo igual decir pudiera

el furor destos bárbaros guerreros,

viendo el valor del mundo en ellos junto

y la encendida cólera en su punto! (Ercilla XXIX.29)

Claro está, para Ercilla, la representación favorable del enemigo se refleja en el verdadero valor de los españoles: "pues no es el vencedor más estimado / de aquello en que el vencido es reputado" (Ercilla I.2). La muerte recibida es, como en el caso de Catón ("en sus mismas entrañas"), no solamente una señal de resistencia patética, sino también metáfora de la guerra civil. Además, la mención de la batalla de Lepanto es explícitamente comparada con la de Actium, marcando la confrontación fatal en la Farsalia. Lepanto representa, por supuesto, el triunfalismo del imperio español, su victoria sobre las fuerzas de los incrédulos (Ercilla XXIII.73). Sin embargo, la asociación de Lepanto con

13. En modo parecido, Marrero-Fente (117-21) demuestra cómo la virtud ejemplar de la indígena Tegualda, su piedad, alcanza un significado universal a través de correspondencias textuales con Virgilio y Estacio. 
el combate de Actium (“donde se definió la gran porfía, entre César Augusto y Marco Antonio"; Ercilla XXIII.77) deja abierta la posibilidad de ver a los españoles como los enemigos del cesarismo oriental (Fuchs 44; Quint 157; Martínez 133).

La reelaboración del modelo épico por Ercilla se distingue por una casi identificación de los partidos opuestos, y por eso la guerra aparece sobre todo como un teatro trágico. Para Ercilla, la resistencia continua de los araucanos impide la clausura ideológica del poema. En el caso de Anchieta, la influencia de Lucano es responsable, sí, de una cierta ambigüedad o simetría en la representación de una violencia feroz. La violencia de los portugueses en todo caso se justifica y sublima a partir de los valores del imperialismo cristiano. Así, la influencia innegable de Lucano es mucho más superficial en Anchieta y no llega a perturbar la forma estructuralmente suelta, aunque ideológicamente clausurada, del poema brasileño. Los versos finales expresan la convicción de que la conversión de los indios brasileños a la imagen de Cristo va a permitir un "siglo de oro". En La Araucana tenemos, por lo contrario, una perspectiva más abierta: el barco de la Fortuna, que es al mismo tiempo el barco del poeta, está "lejos del fin y puerto deseado" ("no puede andar muy lejos ya mi nave"; Ercilla XXXVII. 71). En relación con sus culturas destinatarias (los poderes coloniales de Portugal y España) los poemas de Anchieta y de Ercilla ya no pueden reinscribir y afirmar una visión del pasado conectada de modo teleológico con la época presente. La circunstancia de que, por un lado, los escenarios representados estén tan distantes del centro del poder y que, por otro lado, los eventos sean tan recientes e inconclusos impiden un progreso hacia un cumplimiento, una conclusión en el sentido de la épica virgiliana (Kennedy 147). Anchieta -solo en parte- y Ercilla se inscriben, por lo contrario, en la tradición épica de Lucano. El primero elige la opción del providencialismo cristiano (tal vez una forma de llegar a un telos transcendente sin un desarrollo lineal); el segundo, adoptando el modelo del romanzo dentro el género épico, elige el gesto de la suspensión en el acto de escribir ("Que el disfavor cobarde [...] me suspende la mano"; Ercilla XXXVI.73). Este sentido de un "fin abierto" se corresponde con la inseguridad acerca del desarrollo futuro del imperio de Felipe II (Fuchs 46-47). Como hemos visto, estas dudas, o la imposibilidad de presentar una progresión teleológica, son responsables de una ambivalencia ideológica y de la movilidad semántica de las categorías éticas "furor" y "valor". 


\section{OBRAS CITADAS}

Anchieta, Joseph de. De Gestis Mendi de Saa: Poema epicum. Ed. Armando Cardoso. São Paulo, 1970.

Andrade, Oswald de. "Manifesto Antropófago". A Utopía Antropofágica. São Paulo, 1990. 47-52.

Bakhtin, M. M. "Epic and Novel". The Dialogic Imagination: Four Essays. Ed. Michael Holmqvist. Austin: Texas UP, 1981. 3-40.

Briesemeister, Dietrich. "Das erste Brasilienepos: José de Anchietas De gestis Mendi de Saa (1563)". Ex oriente lux: Festschrift für Eberhard Gärtner zu seinem 60. Geburtstag. Eds. Sybille Große y Axel Schönberger. Frankfurt am Main: Valentia, 2002. 545-65.

Cañizares-Esguerra, Jorge. Puritan Conquistadors: Iberianizing the Atlantic, 1550-1700. Stanford: Stanford UP, 2006.

Conte, Gian Biagio. The Rhetoric of Imitation: Genre and Poetic Memory in Virgil and other Latin Poets. Trad. Charles Segal. Ithaca/London: Cornell up, 1986.

Conte, Gian Biagio. La letteratura latina: manuale storico dalle origini alla fine dell'impero romano. Firenze: Le Monnier, 1992.

Ercilla, Alonso de. La Araucana. Ed. Isaías Lerner. Madrid: Cátedra, 2002.

Frohwein de Salles Moniz, Fábio. "Poesia novilatina nos trópicos: o nativismo embrionário de Anchieta em De gestis Mendi de Saa". Ágora: Estudos Clássicos em Debate 16 (2014): 189-203.

Fuchs, Barbara. Mimesis and Empire: The New World, Islam, and European Identities. Cambridge: Cambridge UP, 2001.

González Luis, José. "De Gestis Mendi de Saa: Ejemplo de épica tradicional”. De Roma al siglo XX. Ed. Ana María Aldama. Vol. 2. Madrid: Sociedad de Estudios Latinos, 1996. 717-29.

Kennedy, Duncan F. "Virgilian Epic". The Cambridge Companion to Virgil. Ed. Charles Martindale. Cambridge: Cambridge UP, 2006. 141-54.

Lagos, Ramona. "El incumplimiento de la programación épica en La Araucana". Cuadernos americanos 40 (1981): 157-91.

Lestringant, Frank. "Fictions de l'espace brésilien à la Renaissance: L'Exemple de Ganabara”. Arts et legendes d'espaces. Paris: Presses de l'Ecole Normale Superieure, 1981. 205-56.

Lucano. The Civil War (Pharsalia). Trad. J. D. Duff. Loeb Classical Library. Cambridge, Mass.: Harvard UP, 1988. 
Lucano, M. Anneo. Farsalia. Trad. Antonio Holgado Redondo. Madrid: Gredos, 1984.

Lupher, David A. Romans in a New World: Classical Models in Sixteenth-Century Spanish America. Ann Arbor: Michigan Up, 2003.

Mahlke, Kirsten. Offenbarung im Westen: Frühe Berichte aus der Neuen Welt. Frankfurt am Main: S. Fischer, 2005.

Marrero-Fente, Raúl. Poesía épica colonial del siglo XVI: bistoria, teoría y práctica. Madrid: Iberoamericana/Frankfurt am Main: Vervuert, 2017.

Martínez, Miguel. Front Lines: Soldiers' Writing in the Early Modern Hispanic World. Philadelphia: Pennsylvania UP, 2016.

Metcalf, Alida C. Go-Betweens and the Colonization of Brazil: 1500-1600. Austin: Texas UP, 2005.

Moura, Alessandro Rolim de. "«Love of War» and «Fierce Tigresses»: Statius, Lucan and Anchieta's De Gestis Mendi de Saa". New Voices in Classical Reception Studies 11 (2016): 1-17.

Nicolopulos, James. The Poetics of Empire in the Indies: Prophecy and Imitation in La Araucana and Os Lusíadas. The Pennsylvania State UP, 1996.

Pereira, Paulo Roberto. "De Gestis Mendi de Saa. A Trajetória de um livro". José de Anchieta, De Gestis Mendi de Saa. Edição facsimilar. Ed. Eduardo Portella. Rio de Janeiro: Fundação Biblioteca nacional, 1997. 4-29.

Quint, David. Epic and Empire. Politics and Generic Form from Virgil to Milton. Princeton: Princeton UP, 1993.

Rabelais, François. Les Cinc Livres. Gargantua. Pantagruel. Le Tiers Livre. Le Quart Livre. Le Cinquième Livre. Eds. Jean Céard, Gerard Defaux y Michel Simonis. Paris: Le Livre de Poche, 2011.

Rodríguez-Pantoja, M. "Las fuentes clásicas en el De Gestis Mendi de Saa de José de Anchieta". Fortunatae 16 (2005): 259-69.

Virgilio. Eclogues. Georgics. Aeneid, Bk. 1-6. Trad. H. Rushton Fairclough. Loeb Classical Library. Cambridge, Mass.: Harvard UP, 1986. 